\title{
Lean-Production-Methods for XXL-Products
}

\author{
DIPL.-WIRT.-ING. DIPL.-ING. [FH] JENS-MICHAEL POTTHAST \\ DIPL.-ING. OEC. SVEN BAUMGARTEN \\ INSTITUT FÜR INTEGRIERTE PRODUKTION HANNOVER GGMBH, HOLLERITHALLEE 6, 30419 HANNOVER
}

\begin{abstract}
Zusammenfassung
In diesem Beitrag werden Charakteristika zur Beschreibung von XXL-Produkten diskutiert und grundlegende Aspekte hinsichtlich des Aufbaus (z. B. Prinzipien, Methoden) von Produktionssystemen vorgestellt. Im Rahmen einer Expertenbefragung bei XXL-Herstellern werden die am häufigsten eingesetzten Lean-Methoden der Produktionssysteme identifiziert. Der Beitrag stellt die Ergebnisse der Expertenbefragung vor und schließt mit einem Ausblick über das weitere Vorgehen ab.
\end{abstract}

\begin{abstract}
This paper discusses the different characteristics used to describe XXL-products and, furthermore, presents fundamental aspects concerning the construction (e.g. principles, methods) of production systems. A survey of experts at XXL-producers is used to identify the most commonly implemented Lean-Production-Methods of production systems. The article presents the survey results and finally concludes with an outlook on further steps.
\end{abstract}

\section{Introduction}

In addition to the trend towards miniaturization (e.g. electrical engineering), there is a trend in the manufacturing business towards macroscopic products, hereinafter referred to as XXL-products. Examples of XXL-products are wind turbines, airplanes, ships or conveyor systems for port operations. During the manufacturing of these products, it is necessary for the manufacturers to distinguish themselves from their competitors by reducing production costs. The introduction of a production system is a potential approach to reducing logistic costs. This goal is reached by a reduction of waste. The IPH is currently working on the subproject „Configuration of Lean Production Methods for Company Specific Systems to the Production of Large-Scale-Products" as part of the cooperation project "Innovations for the Production of Large-Scale-Products" (MWK 11.2-76221-99-2/10), which is supported by the ,Ministerium für Wissenschaft und Kultur' (Ministry of Science and Culture) and the ,Ministerium für Wirtschaft, Arbeit und Verkehr des Landes Niedersachsen` (Ministry of Economy, Labour and Transport of Lower Saxony).

\section{XXL-Products}

Typical characteristics of XXL-products are their large dimensions and heavy weights [Beh-09]. The rotor blade diameter of a wind turbine e.g. was about $15 \mathrm{~m}$ wide in 1980 and approximately $126 \mathrm{~m}$ in 2010 [Web-10]. Further specific features of XXL-products are listed morphologically in Figure 1. The morphology is structured by product and production, and describes characteristics of criteria (e.g. complexity, costs) for XXL-products compared to automobiles. Four different XXL-product-manufacturers (e.g. of airplanes and ships) participated in the XXL-survey. The survey lacks statistical significance due to the relatively small number of participants. However, they provide a good impression of the characteristics of the criteria for XXL-producers.

XXL-products are multi-part complex products in terms of their complexity compared to an automobile. A cruise ship for example contains about six million parts and 500 assemblies. The production costs per unit for a cruise ship are about $€ 500$ million and thus considerably higher than in the automotive manufacturing [Bmw11], and the annual sales volumes are low compared to the automotive industry. The worldwide production of barges for example was about 3.500 units in 2010 [Bmw-11]. The number of suppliers and the vertical integration are higher than in the automotive industry. Other criteria to distinguish XXL-products from conventional products are lower stocking and transport possibilities and lower work plan quality. The production of XXL-products results in a lower timing of the process steps, a high fluctuation of capacity requirements and a much lower data availability (e.g. documentation of production progress) than in the automobile production. The morphology indicates that a variety of criteria is necessary to describe and manufacture XXL-products. 


\begin{tabular}{|c|c|c|c|c|c|c|c|}
\hline & Criterion & \multicolumn{6}{|c|}{ Expression (Comparison between XXL-Products and Automotive) } \\
\hline \multirow{8}{*}{$\begin{array}{l}\text { 늠 } \\
\text { 응 } \\
\text { 음 }\end{array}$} & Komplexität & \multicolumn{2}{|l|}{ Low-Part Article } & \multicolumn{2}{|c|}{$\begin{array}{l}\text { Multi-Piece Article } \\
\text { (simple structure) }\end{array}$} & \multicolumn{2}{|c|}{$\begin{array}{l}\text { Multi-Piece Article } \\
\text { (complex structure } 88\end{array}$} \\
\hline & Costs & much lower & lower & & equal & higher $\bullet$ & much highe? \\
\hline & Sales Volume per Year & much lower & lower & $\bullet$ & equal & higher & much higher \\
\hline & Number of Suppliers & much lower & lower & $\bullet$ & equal & higher & much higher \\
\hline & Vertical & much lower & lower & & equal & higher 0 & much higher \\
\hline & Shelf Life & much lower & lower & $\bullet$ & equal $\bullet$ & higher & much higher \\
\hline & Transportability & much lower & lower & $\bullet$ & equal & higher & much higher \\
\hline & Quality of the Work Plan & much lower & lower & & equal & higher & much higher \\
\hline 동 & $\begin{array}{c}\text { Poss. Cycle-Time of Process } \\
\text { Steps }\end{array}$ & much lower & lower & & equal & higher & much higher \\
\hline$\frac{t}{\frac{t}{0}}$ & $\begin{array}{l}\text { Fluctuations of Capacity } \\
\text { Requirements }\end{array}$ & much lower & lower & & equal & higher & much highe? \\
\hline 는 & Data Availability & much lower & lower & • & equal & higher & much higher \\
\hline
\end{tabular}

Figure 1: Morphology of XXL-products compared with the automobile

A criteria change represents an enormous challenge for XXL-manufacturers. The criteria "timing of process steps" as used in the assembly line represents a special task for example, since the assembly object is moved in this assembly principle. Contrary to the assembly principle 'moving assembly object', the assembly principle 'fixed-site production' requires an assembly at a fixed location. XXL-products are usually made in fixed-site production due to their components' size and weight. A possible timing of process steps makes a considerable impact on the production costs. Therefore continuous production enables a higher degree of automation and thus a higher productivity than other manufacturing principles. The exemplified specific characteristics of the production of XXL-Products require innovative solutions to fulfill the purpose of exploiting organizational improvement regarding the production costs.

\section{Production Systems}

The necessary approaches and methods are provided in so called production systems. In the literature, production systems are defined as company specific methodological rules and regulations for comprehensive and integrated design of the production [Dom-06]. The most commonly used production systems are composed of three elements: methods, principles and targets [Bar-05]. Production systems are used to follow objectives. Each principle (e.g. pull principle) includes various methods (such as Just-in-Time, Kanban-Cycle or Just-inSequence). The principles are the guiding principles for the design of a production system [Kor-04]. The methods describe a particular procedure that can be used to achieve these goals [Ove-08; Dom-06].

\section{Expert survey with XXL-Manufacturers}

The aim of the survey of XXL-manufacturers conducted by the IPH was, first, to find out about the identification methods used and, secondly, to find the reasons for the non-use of methods. In this survey, ten different XXLmanufacturers (airplanes, ships, agricultural machines and others) assessed the production methods used in their particular companies. Among these companies was only one small and medium enterprise according to the definition by the Institute for SME-Research in Bonn. The experts were interviewed on the basis of a developed catalog with 41 methods. Potential methods for the XXL-production were taken from industry (Audi production system, Hella production system) and science (collection of methods from SpATH, collection of methods from BASINSKI, collection of methods from ULLMANN) and were summarized in a catalog with the name of the method (e.g. 'brainstorming') and a short description (such as 'creative brainstorming in small groups') in order to identify and select appropriate methods. The often used term 'principle' in the context of production systems was not considered in the expert survey to limit unnecessary complexity.

In average, $78 \%$ of the queried methods are applied. This value is lower compared to the automotive industry. The value varies at XXL-manufacturers between $67 \%$ for airplane engineering and $90 \%$ for engineering of agricultural machines. Figure 2 shows the results as a percentage of use of the individual methods (e.g. Just-inTime). 


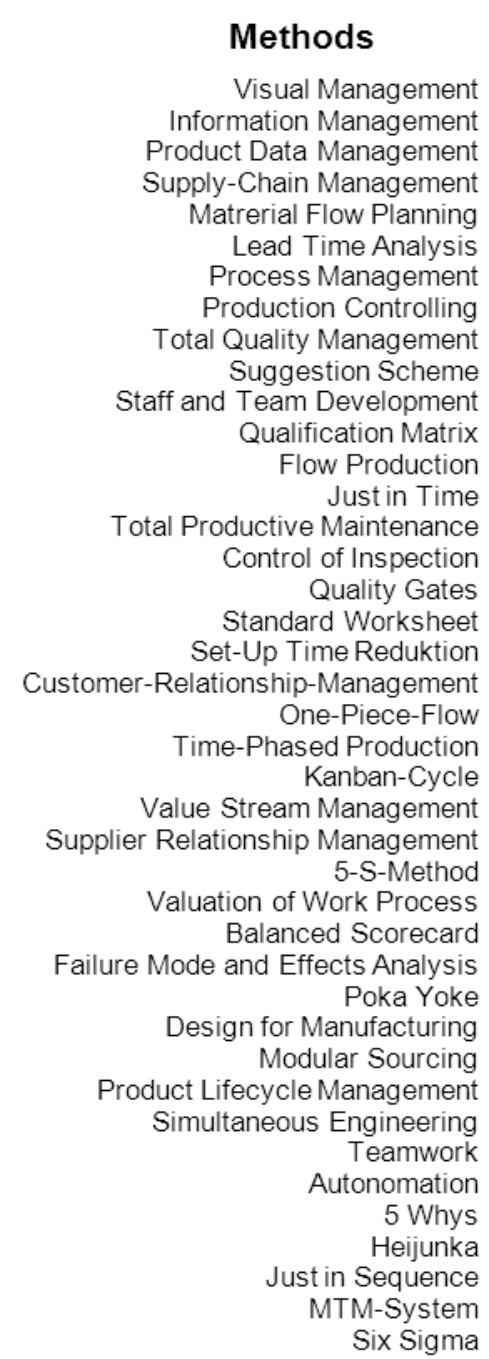

\section{Methods}

Information Management Product Data Management upply-Chain Management Lead Time An Process Management Production Controlling

Total Quality Management Suggestion Scheme Qualification Matrix low Production Maintenance of Inspection Standard Worksheet Set-Up Time Reduktion One-Piece-Flow ased Production Management Management

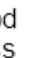

(n)

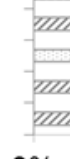

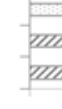
$0 \%$

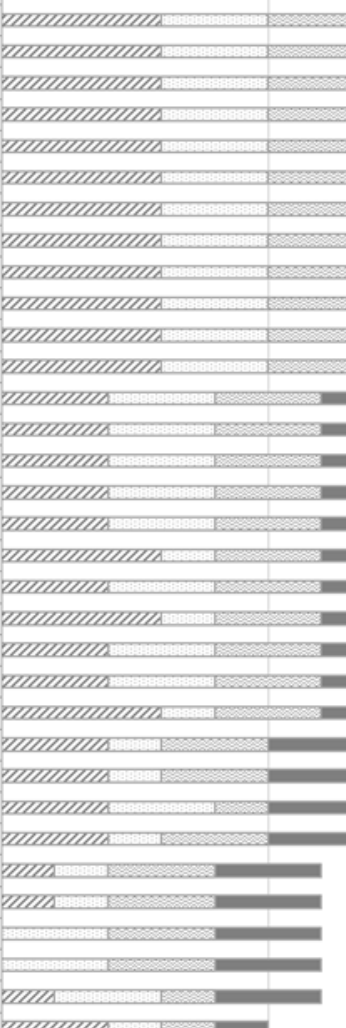$$
50 \%-100 \%
$$

Airplane

$\square$ Ship

Agricultural Machine

n Other

\section{Usage in \%}

Figure 2: Methods used by XXL-Manufacturers

The result of the survey shows that methods like supply chain management, production controlling and total quality management are applied at all XXL-product-manufacturers. Methods which require a high level of automation and standardization like autonomation, hejjunka, MTM-System and Six Sigma are applied less. This result can be traced back to the high complexity of XXL-products, the lower timing of the process steps, a high fluctuation of capacity requirements and a much lower data availability (as shown in Figure 1). Another reason is the high consulting effort which is usually necessary [Har-07; Web-10]. Figure 2 additionally shows the use of different methods in the four different branches aircraft production, agricultural machines production, ship building, and miscellaneous. The figure helps to understand that some methods are only applied in certain XXLbranches. It is apparent that the survey shows a high usage rate in the agricultural machine production which might be related to the similarity of this industry to the automotive industry in which the methods have their origin. Due to this, the adaptation of the methods does not require that much effort. The method Just-inSequence (JIS) for example is only used by $30 \%$ of the XXL-manufacturers, of which $20 \%$ are agricultural machine producers and $10 \%$ belong to the ship industry. This indicates that the surveyed airplane producers still have a high potential with regard to the application of Just-in-Sequence.

The key objective for XXL-manufacturers today and in the future is a sophisticated automation and standardization in the production process to be able to reduce costs. Methods displayed in the catalog can be used to achieve this goal. 


\section{Summary}

Products with large dimensions and high weights are defined as so called XXL-products. Typical examples are airplanes and ships. A morphology was used in order to specify characteristics regarding production and product compared to the automotive industry. XXL-products have a smaller annual sales volume compared to the automotive industry. The lower timing of the process steps on the production side is only one example.

A variety of characteristics is necessary for an explicit description of XXL-products. Additionally, the study describes the methods mostly used by XXL-manufacturers. An expert survey with chosen XXL-manufacturers showed that on average $78 \%$ of 41 asked methods are used. Compared to the automotive industry, this value is low. Possible reasons for the lower usage are the high complexity of the products and the lower standardization and automation of the production. Further research is necessary in order to increase the use of methods at XXLmanufacturers. In this case, the identification of application limits of the flow system and the transfer of some selected advantages from the assembly line production to the fixed site production e.g. could be a lever.

\section{References}

\begin{tabular}{|l|l|}
\hline [Bar-05] & $\begin{array}{l}\text { Barth, Heiko (2005): Produktionssysteme im Fokus. In: wt Werkstattstechnik online. } \\
\text { Jahrgang 95 (2005), Heft 4, S. 269-274. }\end{array}$ \\
\hline [Beh-09] & $\begin{array}{l}\text { Behrens, B.-A., et al. 2009. XXL-Produkte - ein Trend in der Produktion. VDI-Z } \\
\text { Integrierte Produktion. 151. Jg, 2009, 7/8, S. 56-58. }\end{array}$ \\
\hline [Bmw-11] & $\begin{array}{l}\text { Bundesministerium für Bildung und Forschung (BMWi): Maritime Technologien der } \\
\text { nächsten Generation http://www.pt.de/lw_resource/datapool/_items/item_2509/programm- } \\
\text { schifffahrt_barrierefrei.pdf, 4.7.2011. }\end{array}$ \\
\hline [Dom-06] & $\begin{array}{l}\text { Dombrowski, U.; Palluck, M.; Schmidt, S.: Strukturelle Analyse Ganzheit-licher } \\
\text { Produktionssysteme. ZWF 101 (2006) H. 3, S. 114-118. }\end{array}$ \\
\hline [Har-07] & $\begin{array}{l}\text { Harjes, I.-M.; Stechow, M.: Von der Dockfertigung zur Fließfertigung. In: Industrie } \\
\text { Management, Gito-Verlag, 23. Jg. (2007), H. 3, S. 32-34. }\end{array}$ \\
\hline [Kor-04] & $\begin{array}{l}\text { Korge, A.; Scholz, O.: Ganzheitliche Produktionssysteme -Produzierende Unternehmen } \\
\text { innovativ führen. wt Werkstatttechnik online 94 (2004) Nr. 1/2, S. 2-6. Internet: } \\
\text { www.werkstattstechnik.de. Düsseldorf: Springer-VDI-Verlag. }\end{array}$ \\
\hline [Ove-08] & $\begin{array}{l}\text { Overmeyer, L.; Ullmann, G.: Methodenwissen im Werkzeug- und For-menbau: Ergebnisse } \\
\text { einer Studie zum Wissensstand bezüglich Lean-Production-Methoden in der } \\
\text { Unikatfertigung. In: wt-online, Springer VDI Verlag, 98. Jg. (2008), H. 11/12, S. 914-919. }\end{array}$ \\
\hline Web-10] & $\begin{array}{l}\text { Weber, T.: Am laufenden Band. In: neue energie, Bundesverband Wind-energie e. V., 3. } \\
\text { Jg. (2010), H. 4. S. 66 - 73. }\end{array}$ \\
\hline
\end{tabular}

